\title{
Environmental Impact Assessment (EIA) and Strategic Environmental Assessment (SEA): an exploration of synergies through development of a Strategic Environmental Framework (SEF)
}

\author{
P. Cole ${ }^{1} \&$ M. Broderick ${ }^{2}$ \\ ${ }^{1}$ Halcrow Group Ltd, London, UK \\ ${ }^{2}$ Golder Associates, London, UK
}

\begin{abstract}
The synergies between Environmental Impact Assessment (EIA) and Strategic Environmental Assessment (SEA) have often been debated. In the right context, SEA can contribute to the efficiency of the EIA process, for example, when informing the scoping stage of the EIA. It can also compensate for some of the EIAs shortcomings, particularly in the provision of an effective monitoring framework. This paper reports on the SEA carried out on a port and industrial zone master plan in Abu Dhabi, UAE. This assessment is unusual in so much as it is a SEA of a privately funded master plan; is one of the first to be carried out in the Middle East (therefore not subject to EU Directive 2001/42/EC); and has been followed directly by an EIA of the same development. As such it provided a unique chance to adapt the SEA process and fully exploit any possible synergies between the two environmental assessment processes.

Keywords: Strategic Environmental Assessment, Environmental Impact Assessment, Equator Principles, Middle East, master plan, Sustainability, Planning, Strategic Environmental Framework, Environmental Capacity.
\end{abstract}

\section{Introduction}

The Emirate of Abu Dhabi within the United Arab Emirates (UAE), in 2005, committed to the development of a new port and industrial zone within the 
Emirate, the 'Khalifa Port and the Industrial Zone (KPIZ)', located at Al Taweelah (a greenfield site) between Dubai and Abu Dhabi. It is intended that the new port will take up the existing trade of Abu Dhabi's current principal port, Mina Zayed, and will underpin the development of new industries e.g. aluminium smelter, steel mill and trade within the port and industrial zone.

An Environmental Impact Assessment (EIA) was required for the Port and Industrial Zone under UAE Federal Law 24, 1999 [1] and its associated executive orders, which set forth the types of activities for which an EIA is required. In the Emirate of Abu Dhabi the "Competent Authority" for the implementation of this Law is the Environment Agency Abu Dhabi (EAD). A Marine Infrastructure Impact Assessment (MIIA) to analyse and minimise the impact of the port and industrial zone discharges on the adjacent marine environment was also undertaken. One of the tasks preceding this EIA was the development of a Strategic Environmental Assessment (SEA) to provide guidance during the master planning process.

This paper presents a case study on an adaptation of the standard Strategic Environmental Assessment (SEA) which led to the development of a new tool which we have called a "Strategic Environmental Framework (SEF)". This SEF fed directly into the development of sustainable strategies for project level EIAs. Marshal and Fischer (2006) [2] commented on the paucity of reporting of the application of SEA in the private sector. This paper contributes further to reporting of SEA in the private sector, by innovatively applying an adaption of the standard Strategic Environmental Assessment methodology for a major private sector development in the Middle East, which fed directly into the development of sustainable strategies for project level EIAs.

\section{Assessment process}

The assessments of the different Master Plan alternatives for the Port, Industrial Zone and New Town were to follow a "standard" SEA methodology [3], by using an assessment matrix based around an SEA framework. The SEA Framework would be made up of a series of environmental objectives and criteria which were derived from environmental issues and opportunities identified within the reviews of the baseline and relevant policies, plans and programmes.

Each alternative was to be assessed against every SEA criteria and the scores then combined to produce an overall assessment score for each alternative. This method not only allows the total environmental impact of each alternative to be compared next to the do-nothing scenario, but also highlights the environmental issues attached to a particular alternative.

The results of the Port, Industrial Zone and New Town assessments were also to be considered in tandem so as to derive an overall preferred alternative for the development as a whole.

However, whilst the "standard" SEA methodology was adopted, a number of opportunities existed to adapt this methodology. 


\subsection{Opportunities}

\subsubsection{Absence of SEA Legislation outside EU}

There is no equivalent of the EU Directive 2001/42/EC (the 'SEA Directive') [4] in the UAE. Importantly this allows a certain level of freedom to change the structure of the process so it could be adapted to the specific situation in Abu Dhabi and in particular the hurdles encountered when carrying out the process.

The requirement for consultation, for example, is one area which was adapted to suit the situation. Within the study area for the KPIZ project there is very little residential population. Indeed, numbers are so small that a comprehensive consultation exercise was carried out on an individual basis, (the Social Impact Assessment prepared in advance of the EIA performed this function). For these reasons regulatory consultation was conducted solely with the 'Competent Authority' for looking after environmental affairs in Abu Dhabi: the Environmental Agency Abu Dhabi (EAD). The SEA was, in this situation, merely designed to be a tool to input timely environmental information into the Master Planning process; information which the planners could use as they saw appropriate.

Once the Master Planners started developing options, these could immediately be assessed for their environmental impact. Crucially, the reviews of baseline data and relevant policies, plans and programmes, helped identify key environmental issues and opportunities within the study areas. It was this input into the Master Planning process that is perhaps the most important as it allowed these environmental issues and environmentally sensitive areas to be avoided at a planning stage where the option of avoidance was still possible.

\subsubsection{Monitoring framework}

As in all Strategic Environmental Assessments, the SEA Report includes a monitoring framework. This is not normally covered by project level EIA [5, 6]. The monitoring framework provides an important basis to any Environmental Management Plans (EMPs) produced for the developments. This allows the effectiveness of the SEA and EIA to be monitored and contributes to any national/regional monitoring framework subsequently developed by National authorities. The latter benefit is of particular relevance to this proposed development and region. This is also an important aspect for project financing provided under the Equator Principles [7]. The Equator Principles are based on the policies and guidelines of the World Bank and International Finance Corporation (IFC) and the project finance for a number of the planned developments in the Industrial Zone will be sourced from independent financial institutions who subscribe to the Equator Principles. In adopting the Equator Principles, a bank undertakes to provide loans only to those projects whose sponsors can demonstrate to the satisfaction of the bank their ability and willingness to comply with comprehensive processes aimed at ensuring that projects are developed in a socially responsible manner and according to sound environmental management practices. 


\subsubsection{Incorporation of environmental concerns at the planning stage}

A major conclusion of the 'Marine Conservation Forum, 2006' held in Abu Dhabi [8], was that there was a need to incorporate environmental concerns at the planning stage rather than as a mitigation strategy mid-way through project implementation'. This statement refers to the way in which environmental input into the planning process for the majority of proposed developments within the Gulf region often occurs when proposals are already developed in some detail. This therefore necessitates that any changes to proposals on environmental grounds normally take the form of mitigation measures that are limited in their scope.

SEA and our adaptation of SEA process provide the opportunity to provide timely environmental inputs at the earliest stages of the planning process. The environmental context can be developed prior to commencement of the Master Planning process or even during site selection.

\subsection{Hurdles}

\subsubsection{Collation of baseline data}

Master Plans, by their very essence, tend to be concerned with a delineated area, smaller than many other Policies, Plans and Programmes (PPPs) subjected to SEA. In addition, the proposed utilisation of the study area is usually more defined than for a 'typical' development plan. This makes the importance of baseline data relating to the locality and the study area even more important.

Within Abu Dhabi, environmental management and monitoring systems on a national, regional or local scale are either not in existence or still relatively new. Much of the environmental information for the SEA had to be taken from dated sources and in general a lot of the existing condition was inferred from an international level data source. This posed the problem that much of the information was non-specific to the study area.

\subsubsection{Review of relevant policies, plans and programmes}

A review was undertaken of plans, programmes and environmental protection objectives relevant to the KPIZ Master Plans at an international, national, regional, and local level. Access to these documents, much like the baseline data collation, was relatively simple at the international level. However, national and local level strategies, policies and plans were harder to source.

To obtain any particular strategy or environmental law, might typically involve a convoluted administrative process, including the scheduling of meetings with the EAD and ending with the need to translate the documents from Arabic into English. The resulting review was more time consuming than expected and due to this some documents were not examined fully.

\subsubsection{Lack of Master Planning Input}

The Port Master Planning process commenced in September 2005, with the SEA process running alongside it. However, the appointment of master planners for the Industrial Zone and New Town became delayed. It was at this point that a strategic environmental capacity study with outputs that could feed into the 
Industrial Zone Master Planning process at its earliest point was envisaged. This and the hurdles and opportunities identified, was the main driver for developing the 'Strategic Environmental Framework' approach, which was not reliant on the Master Planners already being in place. Instead, the 'Strategic Environmental Framework' (SEF) laid the constraints within which these Master Planners should work upon their eventual appointment. This was married with the SEA of the Port Master Plan to form an SEA incorporating SEF.

\section{Development of the Strategic Environmental Framework (SEF)}

The SEF provided an opportunity to highlight:

- $\quad$ environmental threshold levels;

- reveal headroom capacities;

- $\quad$ suggest guideline emissions levels; and

- recommend potential mitigation measures to the Industrial Zone Master Planners when appointed, so that they might incorporate these factors at the earliest point in the development of their options, with the aim of progressing their proposals within the environmental limits delineated within the Strategic Environmental Framework (SEF) studies.

Figure 1 illustrates how these threshold levels and headroom capacities were derived for environmental aspects relevant to air quality, water quality, noise, and soil / groundwater quality.

Step 1: Establishing the baseline - The majority of this data was obtained from EIA baseline surveys and hence was both specific to the study area and current.

Using the air quality measurements as an example, monitoring of ground level concentrations of key pollutants using a fixed monitoring station located within the study area, provided the ambient air quality baseline. A summary was derived from hourly average measurements for the five month period 1 January 2006 to 31 May 2006. Where assumptions were made and where baseline data didn't exist, this was made clear.

Step 2: Setting of thresholds and other constraints - requires the identification of relevant thresholds and targets relating to the different environmental variables examined in Step 1. These thresholds values should be commensurate with environmental protection legislation; however, there may be instances where adjustment is needed to avoid severe impacts upon particular receptors present given the often extreme existing conditions e.g. sensitivity of corals to ambient water temperatures which already occasionally reach threshold levels in the Abu Dhabi study area during the summer months. Thresholds and targets may not apply uniformly across the whole study area, and where appropriate they should reflect the proposed land use for a particular area. 
Step 3: Identifying 'Headroom' - put simply, this involves calculating the net difference between the thresholds and targets adopted for each environmental aspect, and the baseline conditions established in Step 1.

Steps 1 to 3 were used for KPIZ development and within themselves provided a valuable input to Industrial Zone Master Planning process that was to follow. Steps 4, 5 and 6 represent a number of further stages through which the Strategic Environmental Framework could progress.

Step 4 would be to allocate further headrooms to the Port and individual industries proposed for the Industrial Zone. Step 5 would be to identify potential compliance issues in terms of headroom capacity assigned to each industry. Step 6 would be a regular and ongoing review of the appropriateness of the SEF, which would last the life of the development.

Steps 4 and 5 would require more detailed design information from the Industrial Zone Master Planners and tenant industries, so as to be able to more accurately calculate individual headroom capacities.

If Step 6 was to be adopted, it should occur at regular intervals throughout the lifetime of the developments and would be most effectively integrated within both development-wide and site-specific Environmental Management Plans. During the life of the Khalifa Port and Industrial Zone, there will be a need to review the thresholds, headroom and allocation of headroom as the findings of the monitoring programme become known. There is also likely to be a need to review the framework in light of potential tenants coming to the Industrial Zone, new legislation and technology becoming available, other proposed nearby developments, creation of protected areas and/or other unforeseeable events.

\section{Synergies of SEA process with the EIA process}

In this section we will explore and discuss the synergies between the SEA and EIA process.

The adaptation response to the baseline data availability and access issues was based around the iterative nature of SEA (and in particular, the updating of baseline data at all stages during the process). During the initial stages of the SEA, the baseline data was collated and inferred for the most part, from international data sources. Later during the SEA and SEF process, local data was updated with information derived from EIA baseline surveys.

It would not be normal practice to mix the two data 'levels'. However, with the lack of local baseline data, and the importance of this data to the process (due to the SEA being of a Master Plan of small and defined spatial area of approximately $100 \mathrm{~km}^{2}$. This approach proved a useful synergy. The SEA and SEF provided a useful forum for all the different sets of EIA baseline data to be displayed and analysed at a strategic level, sometime before it would have been possible with the EIA. This allowed identification of cumulative impacts and also those environmental aspects which should be given particular consideration by the more detailed project level analysis afforded by the EIAs. 


\section{STEP 1: ESTABLISHING THE BASELINE}

Establish baseline conditions for offshore and onshor (for Areas A and C only at this stage) in terms of air quality, noise etc.
Review in terms of other plans \& programmes for resetting of 'future' baseline offshore and onshore (in Areas $\mathrm{A}$ and $\mathrm{C}$ only at this stage).

\section{STEP 2: SETTING OF THRESHOLDS \& OTHER CONSTRAINTS}

Identify main receptors inside/outside the Site (residential housing, terrestrial and marine flora/fauna) - to establish threshold values required to be defined. There are likely to two different sets of limits
relating to human health that will be applicable to inside and outside of the Site.

Look up Abu Dhabi thresholds - noise, air quality, water quality etc.

Look up threshold values - main pollutants: given in "Pollution Prevention and Abatement Handbook", World Bank, 1998

Look up international standards and guidelines (e.g. WHO) to cover gaps in Abu Dhabi and World Bank standards that should meet the Equator Principles.

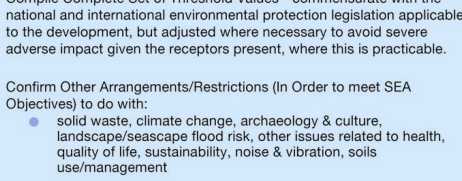
national and international environmental protection legislation applicable to the development, but adjusted where necessary to avoid severe

Confirm Other Arrangements/Restrictions (In Order to meet SEA Objectives) to do with:

solid waste, climate change, archaeology \& culture, solid waste, climate change, archaeology \& culture,
landscape/seascape flood risk, other issues related to health, quality of life, sustainability, noise \& vibration, soils use/management

\section{STEP 3: IDENTIFY "HEADROOM"}

Establish environmental "headroom", i.e. the net differences between Establish environmental "headroom", i.e, the net differences between Areas $\mathrm{A}$ and $\mathrm{C}$ only at this stage).

STEP 4: ALLOCATE "HEADROOM" TO THE PORT, INDUSTRY \& NEW TOWN

For the construction, operation and decommissioning phases of development:

2 Quantify emissions from the Port and associated works

Quantify emissions from the Port and associated works

on the spatial layout of the $\mathrm{IZ}$ and NT and emissions

from industry in the form of an 'Industrial Activity Impacts Table'

Obtain from the IZ Master Planner (or others)

information on the spatial layout of the New Town and emissions, e.g. traffic, domestic wastewater.

\section{STEP 5: IDENTIFY POTENTIAL ISSUES \& OPPORTUNITIES}

Figure 1: Flow diagram for approach to Strategic Environmental Framework.

Many SEA's carried out on plans, programmes or strategies are not focussed on particular developments and therefore do not precede a directly linked Environmental Impact Assessment (EIA). This SEA, however, focuses on a number of large developments all of which will be subject to a discrete EIA [2], and as such it provides a valuable opportunity to exploit the synergies between the two processes, and to introduce the SEF process.

The SEA through the SEF process can provide a framework of headroom capacities for individual environmental aspects, within which the Master Planners can develop their proposals. This framework can then be refined during the preparation of the Environmental Impact Report [2], to take account of the 
individual parts of the development, and even the individual industries (Steps 4 and 5, Figure 1). In this way the SEA / SEF sets the overarching environmental constraints which both the EIA of the overall KPIZ Master Plan, and the project specific EIAs for industries within the industrial zone, must further develop.

Secondly, the SEA allows the environmental impacts of the development to be considered in the context of other developments in the region, enabling informed speculation of what the cumulative impacts on the region might be. As this is done before the EIA, it allows the EIA to take these findings into account when confirming its scope and delineating environmental thresholds.

Thirdly, the SEA includes formulation of a monitoring framework which is not normally covered by an EIA $[5,6]$. This monitoring framework will provide an important basis to any Environmental Management Plans (EMPs) produced for the developments (an important requirement of the Equator Principles [7]); allow effectiveness of the SEA and EIA to be monitored and contribute to any national/regional monitoring framework developed.

Most importantly, the SEA and SEF can help to focus the EIA on the significant environmental issues through its identification of environmental issues and opportunities. The review of relevant plans and programmes; baseline conditions and environmental thresholds / targets, along with the assessment of master plan options themselves, all contribute to this process. The SEA and SEF focus on macroscopic impacts and assesses them at a strategic level. In this way, the SEA SEF provide an effective and rigorous scoping study which should ensure that the findings of the EIA should reveal no significant surprises in terms of environmental impact.

\section{Conclusions}

To conclude, the SEF is a valuable tool that can be used pre-master planning at a point when environmental inputs are at present lacking in many master planning processes which are:

- concerned with large scale development or sets of developments;

- privately funded $[2,7]$

- outside of EU planning constraints [4];

- $\quad$ subject to 'fast-track' planning process (i.e. 1 to 2 years between start of master planning and construction).

The main weakness of the SEF approach lies mainly in its reliance upon a detailed baseline. An increasing amount of large scale development (warranting master plans), however, is found in geographical areas where baseline data is sparse. The SEF is therefore intrinsically dependent upon subsequent EIAs. The 'traditional' SEA stage, whilst being useful during master plan option development, is given less significance due to the SEF process already having constrained the planning process to a set of environmental limits.

The SEF provides a set of environmental constraints within which master planners can develop all options and provides the environmental scoping for all subsequent SEAs and EIAs within the study area. 


\section{Acknowledgements}

Thanks to Dr Bridget Durning of the Oxford Institute for Sustainable Development (OISD) at Oxford Brookes University for comments on earlier drafts of the paper.

\section{References}

[1] UAE Federal Law 24, 1999.

[2] Marshall, R. \& Fischer, T. B., Regional Electricity Transmission Planning and SEA: The Case of the Electricity Company Scottish Power. Journal of Environmental Planning and Management, 49(2), pp. 279-299, 2006.

[3] Therivel, R., Strategic Environmental Assessment in Action, Earthscan: UK and USA, 2004.

[4] European Directive 2001/42/EC, The Assessment of Certain Plans and Programmes on the Environment (The SEA Directive)

[5] Morris, P. and Therivel, R., Methods of Environmental Impact Assessment, Spon Press: UK.

[6] Morrison-Saunders, A. \& Arts, J., (eds). Assessing Impact: Handbook of EIA and SEA Follow-up, Earthscan: UK and USA, 2004.

[7] The Equator Principles, 2003, www.equator-principles.com

[8] WWF, Minutes of the Abu Dhabi Marine Conservation Forum, Abu Dhabi, UAE, 2006. 